\title{
Cholesterol Reduces the Effects of Dihydroxy Bile Acids and Fatty Acids on Water and Solute Transport in the Human Jejunum
}

\author{
Sohan L. Broor, Thomas Slota, and Helmut V. Ammon, Section of \\ Gastroenterology, Veterans Administration Center, Wood, Wisconsin 53193; \\ Department of Medicine, The Medical College of Wisconsin, Milwaukee, \\ Wisconsin 53226
}

\begin{abstract}
A B S TRACT Jejunal perfusion studies were performed in 16 healthy volunteers to test the hypothesis that intraluminal cholesterol can mitigate the fluid secretion induced by dihydroxy bile acids and fatty acids. Fluid secretion in the presence of $5 \mathrm{mM}$ taurodeoxycholate was somewhat reduced by $4 \mathrm{mM}$ mono-olein which was used for the solubilization of cholesterol. Addition of $0.8 \mathrm{mM}$ cholesterol reduced fluid secretion further $(P<0.05)$. Fluid secretion induced by $4 \mathrm{mM}$ oleic acid was changed to net absorption in a linear fashion with increasing cholesterol concentration in the perfusion solutions. $1 \mathrm{mM}$ cholesterol reduced fluid secretion induced by $6 \mathrm{mM}$ oleic acid $(P<0.005)$, but had no effect on fluid secretion induced by $6 \mathrm{mM}$ linolenic acid. Glucose absorption was generally affected in a similar manner as water transport. In vitro, $1 \mathrm{mM}$ cholesterol reduced monomer activity of $6 \mathrm{mM}$ oleic acid to $72.3 \pm 0.9 \%$ of control and that of linolenic acid to $81.1 \pm 1.7 \%$ of control. Although statistically significant $(P<0.001)$, the difference in the effects of cholesterol on monomer activities of the two fatty acids was rather small and it is unlikely that changes in monomer concentration of fatty acids and bile acids account for the protective effect of cholesterol. The in vivo observations point to a new physiological role for biliary cholesterol: the modification of the response of the small intestine to the effects of dihydroxy bile acids and fatty acids.
\end{abstract}

This work was published in abstract form: 1977. Clin. Res. 25: 308A; 1977. Clin. Res. 25: 569A; 1979. Gastroenterology. 76: 1250 .

Dr. Broor's present address is Division of Gastroenterology, Postgraduate Institute of Medical Education \& Research, Chandigarh-160012, India.

Received for publication 20 August 1979 and in revised form 26 November 1979.

\section{INTRODUCTION}

Dihydroxy bile acids and long-chain fatty acids inhibit intestinal transport of water and electrolytes and can induce intestinal net fluid secretion in man and experimental animals (1-7). In addition, they reduce absorption of organic solutes in the jejunum $(2,6)$ and ileum (7) and enhance solute absorption in the colon $(8,9)$. The effects are thought to be responsible for the diarrhea in certain malabsorption syndromes (10). The mechanism by which they exert these effects is poorly understood. Bile acids and fatty acids have in common their properties as detergents (11). Their effects on intestinal transport are shared by other detergents $(12,13)$ and it is therefore reasonable to assume that their action on the intestine is mediated by a common mechanism. Three hypotheses have been proposed: $(a)$ stimulation of adenyl cyclase (14-16); (b) enhancement of intestinal permeability $(5,8,17)$; and $(c)$ mucosal injury (18-20). Because under normal circumstances the mucosa of the small intestine remains intact, other constituents of postprandial intestinal contents must protect it from the effects of these detergents.

Lecithin, an obligatory constituent of bile, protects the human jejunum (2) and the canine gallbladder (21) from the adverse effects of dihydroxy bile acids. Normally, however, it is hydrolyzed in the jejunum to lysolecithin and fatty acids and lysolecithin by itself also affects water and solute transport adversely (22). Cholesterol, another obligatory component of bile, is not altered in the small intestine and is present in the lumen throughout the gastrointestinal tract. It delays the onset of hemorrhagic cholecystitis in the canine gallbladder when solutions of pure bile acids are introduced into this organ (23). Cholesterol also reduces the permeability of erythrocyte membranes (24) and 
artificial membranes (25) to water and electrolytes. We therefore performed experiments to test whether cholesterol might mitigate the effects of dihydroxy bile acids and fatty acids on jejunal transport processes. Here we report data from jejunal perfusion studies in healthy volunteers that demonstrate the effects of cholesterol on fluid secretion induced by taurodeoxycholate, oleic acid, and linolenic acid. In addition, the effects of cholesterol on monomer activities of the two fatty acids were studied in vitro in an attempt to define some of the mechanisms by which cholesterol might protect the intestinal mucosa.

\section{METHODS}

Materials. Taurine conjugates of bile acids were synthesized as described (26). The purity of the final products was $>98 \%$ by thin-layer chromatography. Cholic acid was purchased from Sigma Chemicals Co., (St. Louis, Mo.) and deoxycholic acid from ICN Pharmaceuticals (Cleveland, Ohio). Oleic acid (cis-9-octadecenoic acid), linolenic acid (cis-9, cis-12, cis-15-octadecatrienoic acid), mono-olein (1-octadecenoylglycerol), mono-palmitolein (1-hexadecenoylglycerol), and cholesterol (all with a purity of $>99 \%$ ) were obtained from Nu Chek Prep (Elysian, Minn.). $\left[1,2-{ }^{14} \mathrm{C}\right]-$ Polyethylene glycol, $\left[1-{ }^{14} \mathrm{C}\right]$ oleic acid $\left({ }^{14} \mathrm{C}\right.$-oleic acid), and $\left[1,2{ }^{3} \mathrm{H}(\mathrm{N})\right]$ cholesterol $\left({ }^{3} \mathrm{H}\right.$-cholesterol) were purchased from New England Nuclear (Boston, Mass.); $\left[1{ }^{14} \mathrm{C}\right]$ linolenic acid $\left({ }^{14} \mathrm{C}\right.$-linolenic acid) from Amersham Corp. (Arlington Heights, Ill.). Bis(trimethylsilyl-)trifluoroacetamide with $1 \%$ trimethylchlorosilane was purchased from Pierce Chemical Corporation (Rockford, Ill.).

Perfusion technique. Jejunal perfusion studies were performed in healthy male volunteers who gave informed written consent. The protocols were approved by the Human Studies Committees of the Veterans Administration Center, Wood, Wisconsin and the Medical College of Wisconsin, Milwaukee, Wis. The perfusion technique, previously described $(2,4)$, employes a four-lumen tube with an occluding balloon at the ligament of Treitz. Perfusion solutions were delivered at $37^{\circ} \mathrm{C}$ at a constant rate of $10 \mathrm{ml} / \mathrm{min}$ just distal to the balloon and were sampled $25 \mathrm{~cm}$ distally by siphonage. Duodenal contents proximal to the balloon were removed by intermittent suction. An additional gastric tube was inserted for aspiration of gastric secretions. Control and test solutions were perfused for $60 \mathrm{~min}$. The first $30 \mathrm{~min}$ were used for equilibration. Samples were collected for six consecutive 5 -min intervals. Steady-state conditions were confirmed by stable concentrations of polyethylene glycol during these sequential sampling periods and all results refer to observations during the steady state $(2,4,6,7)$.

Composition of perfusion solutions and experimental design. Three groups of experiments were performed. In group I we tested the effects of cholesterol on fluid secretion induced by $5 \mathrm{mM}$ taurodeoxycholate in seven subjects. Four solutions were perfused: $(a)$ a control solution; $(b)$ a solution containing $5 \mathrm{mM}$ taurodeoxycholate; (c) a third solution containing, in addition, $4 \mathrm{mM}$ mono-olein as micellar expander for the solubilization of cholesterol (27); and (d) a solution containing, in addition, $0.8 \mathrm{mM}$ cholesterol. The control solution contained (in millimoles per liter): $\mathrm{Na} 130, \mathrm{~K} 5, \mathrm{Cl} 135$, glucose 11.2, polyethylene glycol-4000 $5 \mathrm{~g} /$ liter, and $\left[1,2-{ }^{14} \mathrm{C}\right]$ polyethylene glycol $4 \mu \mathrm{Ci} /$ liter. Osmolality was $280 \mathrm{mosmol} / \mathrm{liter}, \mathrm{pH} 7.3-7.5$.

In groups II and III we studied the effects of cholesterol on fluid secretion induced by fatty acids. All perfusion solu- tions contained (in millimoles per liter): Na 125-130, K 5, Cl 110-115, glucose 11.2, taurocholate 10 for micellar solubilization, polyethylene glycol-4000 $5 \mathrm{~g} / \mathrm{liter},\left[1,2-{ }^{-14} \mathrm{C}\right]-$ polyethylene glycol $4 \mu \mathrm{Ci} /$ liter, $\left[{ }^{3} \mathrm{H}\right]$ cholesterol $16 \mu \mathrm{Ci} /$ liter, and fatty acids and cholesterol. Taurocholate alone at $10 \mathrm{mM}$ has no secretory effect in the human jejunum (4). The concentrations of fatty acids and cholesterol varied with the experimental design. In group II we studied the effects of 0.036 , $0.09,0.18,0.27$, and $0.36 \mathrm{mM}$ cholesterol on fluid secretion induced by $4 \mathrm{mM}$ oleic acid in four subjects. The perfusion sequence of the five solutions was randomized. In group III the effect of $1 \mathrm{mM}$ cholesterol was tested in the presence of two different fatty acids, $6 \mathrm{mM}$ oleic acid (OA) and $6 \mathrm{mM}$ linolenic acid (LA). The sequence of perfusion was LA, LA plus cholesterol; OA, OA plus cholesterol in three subjects; and OA, OA plus cholesterol, LA, LA plus cholesterol in the other two. Cholesterol concentrations in all solutions were below the maximal cholesterol solubility as determined in mixed micellar solutions that simulated the experimental conditions with the method described by Simmonds et al. (27).

Effect of cholesterol on apparent monomer activity of fatty acids in micellar solutions. The effect of cholesterol on monomer activity of fatty acids was studied by the method of Sallee (28). The technique is based on the partitioning of lipids between the monomer phase and a solid organic phase, a polyethylene disk, on the assumption that the lipid interaction with micelles is similar to a phase distribution system. Polyethylene disks were incubated in mixed micellar solutions containing ${ }^{14} \mathrm{C}$-fatty acids and cholesterol. The polyethylene disks, $0.5 \mathrm{in}$. in diameter, were punched from polyethylene film, $0.006 \mathrm{in}$. thick. The disks were washed in methanol and distilled water and were dried before use. The average weight of the disks was $17.8 \mathrm{mg}$ with a range from 17.0 to $18.3 \mathrm{mg}$. Disks falling outside this range were eliminated. All experiments were conducted in $20 \mathrm{mM}$ sodium phosphate buffer, $\mathrm{pH} 7.4$, with $120 \mathrm{mM}$ sodium chloride added to keep sodium concentration similar to the conditions prevailing in the intestinal lumen. All solutions contained, in addition, 10 $\mathrm{mM}$ taurocholate for micellar solubilization, $6 \mathrm{mM}\left[{ }^{14} \mathrm{C}\right]$ oleic acid $\left(3.5 \mathrm{nCi} / \mu \mathrm{mol} \mathrm{sp}\right.$ act), or $6 \mathrm{mM}\left[{ }^{14} \mathrm{C}\right]$ linoleic acid $(36$ $\mathrm{nCi} / \mu \mathrm{mol} \mathrm{sp}$ act) with varying concentrations of cholesterol ranging from 0 to $1 \mathrm{mM}$. The disks were impaled on a needle, placed into $20 \mathrm{~cm}^{3}$ of the test solution in a capped vial under argon atmosphere and equilibrated for $48 \mathrm{~h}$ at room temperature under constant shaking at 100 oscillations/min. After completion of the incubation, the disks were rinsed with $10 \mathrm{mM}$ taurocholate to remove lipids adhering to the surface and placed into a counting vial with $10 \mathrm{~cm}^{3}$ of Ready Solv VI (Beckman Instruments, Inc., Fullerton, Calif.) for determination of radioactivity by liquid scintillation counting. Since disk size, specific activity of the fatty acids, and fatty acid concentration in the incubation solutions remained constant, the change of uptake of radioactivity by the disks under the influence of cholesterol is a direct expression of the changes in monomer activity of the fatty acids. To compare the relative changes in monomer activity induced by cholesterol, the data were normalized by assigning the uptake by the discs in the absence of cholesterol the value $100 \%$ (29). All values are reported as the mean $( \pm \mathrm{SE})$ of six determinations.

Analytical methods. Fatty acids were measured by gasliquid chromatography of the methyl esters after acid extraction in a toluene-ethanol mixture $(2: 1)$ containing heptadecanoic acid as an internal standard (6). Mono-olein was determined by gas-liquid chromatography of the trimethylsilyl ether derivative (30). 1-ml aliquots of samples containing mono-olein were immediately upon collection mixed with 3 $\mathrm{ml}$ of heptane:ethanol:ether $(1: 1: 1)(29)$ containing $1 \mathrm{mg} / \mathrm{ml}$ 
monopalmitolein as internal standard. The upper phase of the mixture was dried under nitrogen and dissolved in $0.5 \mathrm{~cm}^{3}$ of pyridine and $0.2 \mathrm{~cm}^{3}$ of bis(trimethylsilyl-)trifluoroacetamide and $1 \%$ trimethylchlorosilane. The derivatization was complete after about $1 \mathrm{~h}$ at room temperature. Chromatography was performed on a 6 -ft column, $2 \mathrm{~mm}$ internal diameter, on $3 \%$ OV-1 on 80/100 Supelcoport (Supelco, Inc., Bellefonte, $\mathrm{Pa}$.). Column temperature was $250^{\circ} \mathrm{C}$. Cholesterol was determined by gas-liquid chromatography with $\beta$-sitosterol as internal standard (31) or by liquid scintillation counting. Glucose was measured by the glucose oxidase method (Boehringer Mannheim Corp., N. Y.). For isotope determinations $1 \mathrm{ml}$ of perfusion solution or effluent was mixed with $10 \mathrm{ml}$ of scintillation cocktail composed of toluene and emulsifier (Ready Solv VI). The samples were counted in two channels in a liquid scintillation counter (Beckman LS-255). Quench correction was made by external standardization. Counts per minute were converted into disintegrations per minute with a computer program which corrected for quenching and spillover of ${ }^{14} \mathrm{C}$ into the tritium channel (32). Spillover of tritium into the ${ }^{14} \mathrm{C}$-channel was $<1 \%$.

Calculations and statistical analysis. Net water and solute movements were calculated using standard formulas from the changes in PEG and solute concentrations. Results are expressed as mean $( \pm \mathrm{SE})$ of the six 5 -min collection periods. Net water movement is expressed in milliliter per minute per $25 \mathrm{~cm}$ and solute absorption in micromole per minute per 25 $\mathrm{cm}$. Differences in net movement of water and solutes and in the partitioning into polyethylene disks were evaluated statistically by paired or unpaired $t$ tests.

\section{RESULTS}

Water movement. Taurodeoxycholate induced net fluid secretion $(P<0.001)$ (Table I). The addition of mono-olein reduced fluid secretion somewhat; however, the difference was not statistically significant. In the presence of cholesterol, fluid secretion was abolished and net water transport was significantly different from solutions containing taurodeoxycholate
$(P<0.025)$ or taurodeoxycholate plus mono-olein $(P<0.05)$. It did not, however, reach base-line levels $(P<0.05) .4 \mathrm{mM}$ oleic acid induced net fluid secretion (Fig. 1). Increasing concentrations of cholesterol in the perfusion solution changed net fluid secretion to net absorption $(P<0.025) .1 \mathrm{mM}$ cholesterol (Table II) significantly reduced fluid secretion in the presence of $6 \mathrm{mM}$ oleic acid $(P<0.01)$, whereas it had no effect on fluid secretion induced by linolenic acid. In four of the five studies fluid secretion induced by linolenic acid alone was less in comparison with oleic acid. The difference, however, was not statistically significant.

Glucose absorption. Taurodeoxycholate reduced glucose absorption significantly $(P<0.01)$ (Table I). The addition of mono-olein restored glucose absorption to normal. In groups II and III glucose absorption improved when fluid secretion was reduced by the addition of cholesterol $(P<0.05)$.

Lipid absorption. Absorption of mono-olein was not affected by the addition of cholesterol in group I (Table I). No oleic acid was detected in the samples collected during perfusion with mono-olein. Absorption of oleic acid in group II changed from $24.8 \pm 0.9$ to $29.2 \pm 2.0 \mu \mathrm{mol} / \mathrm{min}$ (NS) as fluid secretion was reduced by the addition of cholesterol. In group III oleic acid absorption was enhanced in four out of five studies when fluid secretion was reduced by cholesterol but the difference was not statistically significant. The absorption of linolenic acid was unchanged by the addition of cholesterol. Cholesterol absorption in group I was $2.2 \pm 0.4 \mu \mathrm{mol} / \mathrm{min}$. In group II, cholesterol absorption increased with increasing concentration of cholesterol in the perfusion solution from $0.1 \pm 0.03$ to $1.2 \pm 0.1 \mu \mathrm{mol} / \mathrm{min}$. Cholesterol absorption in the

TABLE I

Reversal of the Effects of $5 \mathrm{mM}$ Taurodeoxycholate on Jejunal Water and Glucose Transport by Mono-olein and Cholesterol

\begin{tabular}{|c|c|c|c|}
\hline \multirow[b]{2}{*}{ Test conditions } & \multicolumn{3}{|c|}{ Absorption $/ 25 \mathrm{~cm}$ jejunum } \\
\hline & Water* & Glucose & Mono-olein \\
\hline$m M$ & $\mathrm{ml} / \mathrm{min}$ & $\mu m o l / m i n$ & $\mu \mathrm{mol} / \mathrm{min}$ \\
\hline 1 Control & $1.2 \pm 0.3$ & $84.0 \pm 10.5$ & \\
\hline 2 TDC 5 & $-1.0 \pm 0.1 \ddagger$ & $59.2 \pm 11.4 \ddagger$ & \\
\hline 3 TDC $5+$ MO 4 & $-0.5 \pm 0.2 \ddagger$ & $81.5 \pm 6.39$ & $32.2 \pm 1.9$ \\
\hline 4 TDC $5+\mathrm{MO} 4$ & & & \\
\hline + Cholesterol 0.8 & $0.09 \pm 0.2 \S \| \rrbracket$ & $77.7 \pm 10.5$ & $29.1 \pm 2.7$ \\
\hline
\end{tabular}

Results are mean $( \pm \mathrm{SE})$ from studies in seven volunteers; each solution was perfused for $60 \mathrm{~min}$ ( $30 \mathrm{~min}$ equilibration) at $10 \mathrm{ml} / \mathrm{min}$; perfusion sequence was randomized. TDC, taurodeoxycholate; MO, mono-olein.

* Negative symbol indicates net secretion.

$\ddagger P<0.01$ vs. 1 .

$\S P<0.05$ vs. 1 .

" $P<0.05$ vs. 3 .

II $P<0.025$ vs. 2 . 


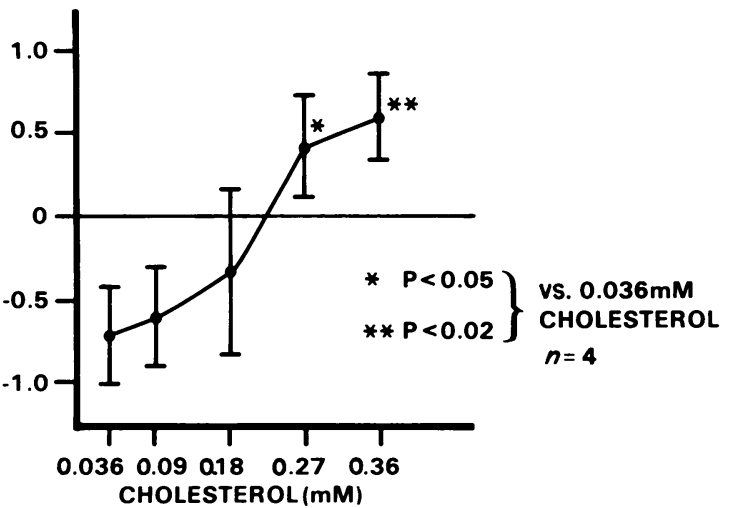

FIGURE 1 Effect of cholesterol on jejunal net fluid secretion induced by $4 \mathrm{mM}$ oleate. Results are mean $\pm S E$ from studies in four healthy volunteers. Perfused were isotonic electrolyte solutions containing, in addition, $10 \mathrm{mM}$ taurocholate for micellar solubilization and $11.2 \mathrm{mM}$ glucose. Each solution was perfused for $60 \mathrm{~min}$ ( $30 \mathrm{~min}$ equilibration) at a rate of $10 \mathrm{ml} / \mathrm{min}$. Perfusion sequence was randomized.

presence of $6 \mathrm{mM}$ oleic acid was $1.8 \pm 0.2 \mu \mathrm{mol} / \mathrm{min}$ and in the presence of $6 \mathrm{mM}$ linolenic acid $0.98 \pm 0.2$ $\mu \mathrm{mol} / \mathrm{min}$. This difference was statistically significant $(P<0.05)$.

Effects of cholesterol on monomer activities (Fig. 2). Addition of cholesterol to mixed micellar solutions significantly reduced the monomer activities of oleic acid and linolenic acid. In the presence of $1 \mathrm{mM}$ cholesterol oleic acid uptake by the polyethylene disks was reduced to $72.3 \pm 0.9 \%$ of the control values; the uptake of linolenic acid was reduced to $81.1 \pm 1.7 \%$

TABLE II

Effect of Cholesterol on Jejunal Transport in the Presence of Fatty Acids

\begin{tabular}{cccc}
\hline & \multicolumn{3}{c}{ Absorption/25 cm of jejunum } \\
\cline { 2 - 4 } Test conditions & Water* & Glucose & Fatty acid \\
\hline m.M & $m l / m i n$ & $\mu m o l / m i n$ & $\mu m o l / m i n$ \\
1 Oleic acid 6 & $-2.1 \pm 0.4$ & $47.7 \pm 8.4$ & $33.2 \pm 2.1$ \\
2 Oleic acid 6 & & & \\
$\quad+$ Cholesterol 1 & $-0.4 \pm 0.4 \ddagger$ & $67.7 \pm 6.1 \S$ & $37.1 \pm 3.1$ \\
3 Linolenic acid 6 & $-1.2 \pm 0.4$ & $56.2 \pm 9.3$ & $34.8 \pm 4.5$ \\
4 Linolenic acid 6 & & & \\
$\quad+$ Cholesterol 1 & $-1.1 \pm 0.5$ & $60.6 \pm 8.1$ & $33.6 \pm 3.3$ \\
\hline
\end{tabular}

Results are mean $( \pm \mathrm{SE})$ from studies in five healthy volunteers. Solutions contained $10 \mathrm{mM}$ taurocholate for micellar solubilization of the lipids. Each solution was perfused for $60 \mathrm{~min}$ (30 min equilibration) at $10 \mathrm{ml} / \mathrm{min}$. Perfusion sequence was $1,2,3$, and 4 in two studies and 3, 4, 1, and 2 in three studies.

* Negative symbol indicates net secretion.

$\$ P<0.005$ vs. 1 .

$\$ P<0.05$ vs. 1 .

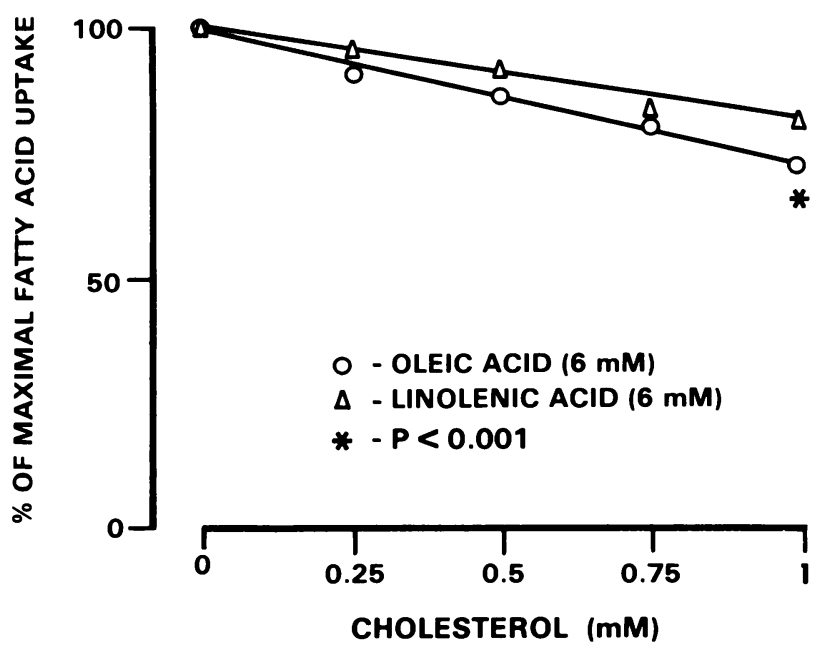

FIGURE 2 Effect of cholesterol on uptake of fatty acids $(6 \mathrm{mM})$ into polyethylene disks. Values are mean of six determinations. SE were too small to be incorporated into the drawing. Polyethylene disks (0.5 in. Diam, 0.006 in. thick) were incubated in $20 \mathrm{~cm}^{3}$ of test solution for $48 \mathrm{~h}$ at room temperature. All solutions contained $10 \mathrm{mM}$ taurocholate, 20 $\mathrm{mM}$ sodium phosphate buffer ( $\mathrm{pH} 7.4), 120 \mathrm{mM}$ sodium chloride, and either $\left[{ }^{14} \mathrm{C}\right]$ oleate or $\left[{ }^{14} \mathrm{C}\right]$ linolenate. For purposes of comparison, lipid uptake by the disks in the absence of cholesterol was assigned the value $100 \%$. ${ }^{*} P<0.001$, difference between oleate and linolenate (unpaired $t$ test).

of control. This change was significantly less than that observed for oleic acid $(P<0.001)$.

\section{DISCUSSION}

The detergent and cholesterol concentrations in these experiments were well within the range of those observed in the jejunum after a meal (33). The data demonstrate that cholesterol can mitigate the effects of taurodeoxycholate and oleate on jejunal water transport in man. To our knowledge, no other experimental data in the intestine are available for comparison. The observations are compatible with the qualitative observation that cholesterol added to solutions of pure bile acids delayed the onset of hemorrhagic cholecystitis in dogs (23) if one assumes that mucosal damage and induction of intestinal fluid secretion are different expressions of the same detergent effect on epithelia (18-20).

For the design of the experiments we assumed that only cholesterol in aqueous solution would be effective. To study the effects in the presence of bile acids a suitable expander of the micellar phase had to be chosen. Mono-olein was selected over lecithin because lecithin inhibits intestinal uptake of cholesterol in vitro (34) and inhibits the absorption of cholesterol in the human jejunum (unpublished observation). Since mono-olein by itself can protect the intestine from the secretory effects of dihydroxy bile acids (35), 
we had to limit the concentration of mono-olein in the perfusion solutions which in turn limited the amount of cholesterol in micellar solution.

The changes in monomer activities of fatty acids induced by cholesterol were small. Moreover, the difference in the effect of cholesterol on the monomer activities of oleic acid and linolenic acid was even smaller and cannot explain the in vivo observations, where cholesterol had a striking effect on fluid secretion induced by oleic acid while no effect was observed in the presence of linolenic acid. A reduction of monomer activity of oleic acid by cholesterol is, therefore, not a likely explanation for this in vivo effect.

The most likely site of action for cholesterol is the cell membrane. In in vitro models, cholesterol alters the fluidity of pure phospholipid membranes and enhances the degree of order within membrane lipids (25). A direct relationship between transport and membrane fluidity has been demonstrated in red cells where an increase in the cholesterol/phospholipid ratio decreased permeability to compounds entering by carrier mediated transport or facilitated a diffusion such as erythritol and glycerol (24). Decrease of membrane fluidity induced by cholesterol prevents stimulation of adenyl cyclase activity by sodium fluoride or by prostaglandin $\mathrm{E}_{1}$ in platelets (37) and adenyl cyclase activity of the rat intestine can be influenced by changes in cell membrane fluidity (38). Other experimental data suggest also that the initial event leading to fluid secretion in response to biological detergents takes place at the cell surface. Conjugated dihydroxy bile acids are poorly absorbed in the jejunum, yet their effects on water and solute transport are dosedependent (2). Lecithin is not absorbed from the jejunum (29) or from the gallbladder (21), but it protects the mucosa against the effects of dihydroxy bile acids $(2,21)$. On the other hand, cholesterol did not protect against the effects of linolenic acid, while cholesterol absorption was significantly reduced under those conditions. This observation would argue in favor of an intracellular effect of cholesterol on water transport. The absorption rate of cholesterol, however, may not reflect its concentration in the cell membrane and the steric configuration of linolenic acid could be the reason for the ineffectiveness of cholesterol. The present data do not allow any more definite statements about the site of action of cholesterol under these circumstances. Studies designed to find an explanation for the different absorption rates of cholesterol are currently in progress.

The observations help to explain why the upper intestine is normally protected from the potentially deleterious actions of bile acids and fatty acids. The lack of protection in the presence of linolenic acid defines some of the limitations of this protective mechanism. Polyunsaturated fatty acids, however, constitute only a small portion of dietary lipids. Biliary cholesterol may, therefore, play an important role in maintaining the integrity of the digestive tract. In view of these observations and the fact that a significant portion of biliary cholesterol is synthesized in the liver (39), the frequently held concept that biliary cholesterol is only an excretory product may need revision. In addition, these observations may provide a stimulus to explore the possibility of using sterols in the management of fatty acid or bile acid induced diarrheas.

\section{ACKNOWLEDGMENTS}

The authors are grateful to Ms. Louise Luedtke, Ms. Michele Andrade, and Mr. Peter Kotvis for their expert technical assistance.

The investigation was supported in part by Research grant AM 17.941 from the National Institutes of Health, U. S. Public Health Service, and by the Medical Research Service of the Veterans Administration.

\section{REFERENCES}

1. Forth, W., W. Rummel, and H. Glasner. 1966. Zur resorptionshemmenden Wirkung von Gallensäuren. NaunynSchmiedebergs Arch. Pharmacol. Exp. Pathol. 254: 364-380.

2. Wingate, D. L., S. F. Phillips, and A. F. Hofmann. 1973. Effect of glycine-conjugated bile acids with and without lecithin on water and glucose absorption in perfused human jejunum. J. Clin. Invest. 52: 1230-1236.

3. Mekhjian, H. S., S. F. Phillips, and A. F. Hofmann. 1971. Colonic secretion of water and electrolytes induced by bile acids: perfusion studies in man. J. Clin. Invest. 50: 1569-1577.

4. Ammon, H. V., P. J. Thomas, and S. F. Phillips. 1974. Effects of oleic and ricinoleic acids on net jejunal water and electrolyte movement: perfusion studies in man. J. Clin. Invest. 53: 374-379.

5. Bright-Asare, P., and H. J. Binder. 1973. Stimulation of colonic secretion of water and electrolytes by hydroxy fatty acids. Gastroenterology. 64: 81-88.

6. Ammon, H. V., P. J. Thomas, and S. F. Phillips. 1977. Effects of long chain fatty acids on solute absorption: perfusion studies in the human jejunum. Gut. 18: 805-813.

7. Krag, E., and S. F. Phillips. 1974. Effect of free and conjugated bile acids on net water, electrolyte, and glucose movement in the perfused human ileum.J. Lab. Clin. Med. 83: 947-956.

8. Chadwick, V. S., S. F. Phillips, and A. F. Hofmann. 1977. Measurements of intestinal permeability using low molecular weight polyethylene glycols (PEG 400). II. Application to normal and abnormal permeability states in man and animals. Gastroenterology. 73: 247-251.

9. Dobbins, J. W., and H. J. Binder. 1976. Effect of bile salts and fatty acids on the colonic absorption of oxalate. Gastroenterology. 70: 1096-1100.

10. Hofmann, A. F. 1972. Bile acid malabsorption caused by ileal resection. Arch. Intern. Med. 130: 597-605.

11. Small, D. M. 1968. A classification of biologic lipids based upon their interaction in aqueous systems. J. Am. Oil Chem. Soc. 45: 108-119.

12. Ammon, H. V., and S. F. Phillips. 1974. Inhibition of ileal water absorption by intraluminal fatty acids. Influence of chain length, hydroxylation, and conjugation of fatty acids. J. Clin. Invest. 53: 205-210. 
13. Sund, R. B., and D. N. Jacobsen. 1978. In vivo reversibility of the jejunal glucose and cation transport alteration caused by intraluminal surfactants in the rat. Acta Pharmacol. Toxicol. 43: 339-345.

14. Racusen, L. C., and H. J. Binder. 1979. Ricinoleic acid stimulation of active anion secretion in colonic mucosa of the rat. J. Clin. Invest. 63: 743-749.

15. Binder, H. J., C. Filburn, and B. T. Volpe. 1975. Bile salt alteration of colonic electrolyte transport: role of cyclic adenosine monophosphate. Gastroenterology. 68: 503-508.

16. Conley, D. R., M. J. Coyne, G. G. Bonorris, A. Chung, and L. J. Schoenfield. 1976. Bile acid stimulation of colonic adenylate cyclase and secretion in the rabbit. Am. J. Dig. Dis. 21: 453-458.

17. Nell, G., W. Forth, T. Freiberger, W. Rummel, and R. Wanitschke. 1975. Characterization of permeability changes by test molecules in rat colonic mucosa under the influence of sodium deoxycholate. In Advances in Bile Acid Research. S. Matern, J. Hackenschmidt, P. Bach, and W. Gerok, editors. F. K. Schattauer, Velag $\mathrm{GmbH}$, Stuttgart, West Germany. 419-424.

18. Saunders, D. R., J. R. Hedges, J. Sillery, L. Esther, K. Matsumura, and C. E. Rubin. 1975. Morphological and functional effects of bile salts on rat colon. Gastroenterology. 68: 1236-1245.

19. Cline, W. S., V. Lorenzsonn, L. Benz, P. Bass, and W. A. Olsen. 1976. The effects of sodium ricinoleate on small intestinal function and structure. J. Clin. Invest. 58: $380-390$.

20. Gaginella, T. S., V. S. Chadwick, J. C. Debongnie, J. C. Lewis, and S. F. Phillips. 1977. Perfusion of rabbit colon with ricinoleic acid: dose-related mucosal injury, fluid secretion, and increased permeability. Gastroenterology. 73: 95-101.

21. Ammon, H. V. 1979. Effect of taurine conjugated bile salts with and without lecithin on water and electrolyte transport in the canine gallbladder in vivo. Gastroenterology. 76: 778-783.

22. Ammon, H. V., L. A. Luedtke, and M. A. Andrade. 1979. Effect of lysolecithin on water and solute transport in the rat jejunum. Gastroenterology. 76: 1091. (Abstr.)

23. Riegel, C., I. S. Ravdin, and C. G. Johnston. 1932. Studies of gallbladder function. VI. The absorption of bile salts and cholesterol from the bile-free gallbladder. Am. J. Physiol. 99: 656-665.

24. Kroes, J. and R. Ostwald. 1971. Erythrocyte membraneseffect of increased cholesterol contents on permeability. Biochim. Biophys. Acta. 249: 647-650.

25. Rothman, J. E., and D. M. Engelman. 1972. Molecular mechanism for the interaction of phospholipid with cholesterol. Nature (Lond.). 237: 42-44.

26. Hofmann, A. F. 1963. The function of bile salts in fat absorption. The solvent properties of dilute micellar solutions of conjugated bile salts. Biochem. J. 89: 57-68.

27. Simmonds, W. J., A. F. Hofmann, and E. Theodor. 1967. Absorption of cholesterol from a micellar solution: intestinal perfusion studies in man. J. Clin. Invest. 46: 874-890.

28. Sallee, V. L. 1974. Apparent monomer activity of saturated fatty acids in micellar bile salt solutions measured by a polyethylene partitioning system. J. Lipid Res. 15: 56-64.

29. Ammon, H. V., P. J. Thomas, and S. F. Phillips. 1979. Effect of lecithin on jejunal absorption of micellar lipids in man and on their monomer activity in vitro. Lipids. 14: 395-400.

30. Watts, R., and R. Dils. 1969. Isomerization of monoand diglyceride trimethylsilyl ethers. Chem. Phys. Lipids. 3: $168-175$.

31. Grunwald, C. 1970. Quantitative analysis of free phytosterols by gas chromatography using stationary phase OV-101. Anal. Biochem. 34: 16-23.

32. Okita, G. T., J. J. Kabara, F. Richardson, and G. V. LeRoy. 1957. Assaying compounds containing $\mathrm{H}^{3}$ and $\mathrm{C}^{14}$. Nucleonics. 15: 111-114.

33. Porter, H. P., and D. R. Saunders. 1971. Isolation of the aqueous phase of human intestinal contents during the digestion of a fatty meal. Gastroenterology. 60: 997-1007.

34. Rampone, A. J. 1972. Bile salt and non-bile salt components in bile affecting micellar cholesterol uptake by rat intestine in vitro. J. Physiol. (Lond.). 227: 889-898.

35. Lamabadusuriya, S. P., E. Guiraldes, and J. T. Harries. 1975. Influence of mixtures of taurocholate, fatty acids, and monolein on the toxic effects of deoxycholate in rat jejunum in vivo. Gastroenterology. 69: 463-469.

36. Tanford, C. 1973. The Hydrophobic Effect: Formation of Micelles and Biological Membranes. John Wiley \& Sons, New York.

37. Sinha, A. K., S. J. Shattil, and R. W. Colman. 1977. Cyclic AMP metabolism in cholesterol-rich platelets. J. Biol. Chem. 252: 3310-3314.

38. Brasitus, T. A., D. Schachter, and T. G. Mamouneas. 1979. Influence of membrane fluidity on rat intestinal adenylate cyclase activity. Gastroenterology. 76: 1106. (Abstr.)

39. Schwartz, C. C., M. Berman, Z. R. Vlahcevic, L. G. Halloran, D. H. Gregory, and L. Swell. 1978. Multicompartmental analysis of cholesterol metabolism in man. J. Clin. Invest. 61: 408-423. 